\title{
Optimization of Inhibitory Peptides Targeting Phosphoprotein of Rabies Virus
}

\author{
Yongzhong Lu' ${ }^{1} \cdot$ Linyue Cheng $^{1} \cdot$ Jie Liu $^{1}$
}

Accepted: 9 August 2019 / Published online: 13 August 2019

(c) Springer Nature B.V. 2019

\begin{abstract}
Rabies is a serious zoonosis caused by rabies virus (RABV) of the genus Lyssavirus, and immunotherapy is now the only approved, effective method for post-exposure prophylaxis against rabies in humans, whereas an effective antiviral therapy is still unavailable if the central nervous system is invaded. Phosphoprotein $(\mathrm{P})$ is known to play pivotal roles in the life cycle of $\mathrm{RABV}$, and has been regarded as a prime target for inhibitors of viral replication. This study aimed to carry out intracellular administration of a kind of P-binding peptide for RABV inhibition. A group of reported P-binding peptides were focused on for activity improvement by quantitative structure-activity relationship (QSAR) method, and then were mediated by cell penetrating peptide (CPP) for intracellular activity evaluation. The QSAR models had good performance in reliability and predictability $\left(\mathrm{R}^{2} \geq 0.852, \mathrm{Q}^{2} \geq 0.601, \mathrm{Q}_{\mathrm{ext}}^{2} \geq 0.595\right)$, and the peptide screened by partial least squares (PLS) QSAR model $\left(\mathrm{R}^{2}=0.994, \mathrm{Q}^{2}=0.937, \mathrm{Q}_{\text {ext }}^{2}=0.981\right)$ exhibited even higher antiviral activity when it was delivered into the cells by CPP. Above all, this study provided an effective way for development of peptide drug against RABV.
\end{abstract}

Keywords Cell penetrating peptides · Descriptor · Post-exposure prophylaxis · QSAR · Vaccination

\section{Introduction}

Rabies is a fatal zoonosis caused by rabies virus (RABV) of the genus Lyssavirus, and has long been a serious public health threat in most areas of the world, especially in the developing countries (Gnanadurai et al. 2015; Yousaf et al. 2012; Zhu and Guo 2016), every year it kills up to 59,000 people worldwide (Lama et al. 2019; Zhu and Guo 2016).

Vaccination combined with administration of RABV neutralizing antibodies, is the only approved, effective method for post-exposure prophylaxis (PEP) against rabies in humans (Zhu and Guo 2016). However, owing to the cost, accessibility and complexity of treatment, PEP usually can't be given promptly and correctly, rabies still has a high death rate (Jackson 2016; Kaur et al. 2015; Lama et al. 2019; Zhu and Guo 2016).

Yongzhong Lu

luyz@qust.edu.cn

1 Shandong Provincial Key Laboratory of Biochemical Engineering, Qingdao University of Science and Technology, No. 53, Zhengzhou Road, 266042 Qingdao, China
Antiviral therapy is thought to be an important component of combination therapy for the management of human rabies, especially for patients who have missed the deadline for valid vaccination or have developed clinical symptoms (Appolinario and Jackson 2015). Till now, no effective therapy can prevent the virus from invading the central nervous system (CNS) once it successfully replicate intracellularly (Banyard et al. 2017; Gnanadurai et al. 2015; Zhu and Guo 2016). Thanks to the progress in RABV molecular biology (Albertini et al. 2011; Lingappa et al. 2013), many targets have been identified for antiviral therapy development (Brunner et al. 2015; Castel et al. 2009; Gumpper et al. 2018; Lama et al. 2019; Meshram et al. 2013; Real et al. 2004; Singh et al. 2014).

The RABV phosphoprotein $(\mathrm{P})$ is a multifunctional protein, besides the role in viral transcription and replication, it can interact with many host proteins to hijack the signaling pathways in favor of viral replication (Fouquet et al. 2015; Masatani et al. 2016; Okada et al. 2016; Wiltzer et al. 2014), or result in mitochondrial dysfunction in neurons causing acute degenerative changes (Kammouni et al. 2015, 2017). Therefore, it is regarded as a promising target for inhibitors development (Albertini et al. 2011; Castel et al. 2009; Kaku et al. 2011). 
Real et al. (2004) once screened out a group of antiviral peptides targeting RABV P from combinatorial peptide libraries, which can be used as new leads for pharmacologically active RABV inhibitors design.

In order to analyze the prospect of these peptides in rabies control, in this work we mainly focused on their optimization as well as intracellular application.

\section{Materials and Methods}

\section{Data Source}

The data of 29 RABV inhibitory peptides targeting RABV $\mathrm{P}$ were retrieved from the literature, a reverse genetic viral ribonucleoprotein (RNP) complex reconstitution assay was used to test the peptide activity, which was negatively correlated with the luciferase intensity (Real et al. 2004). In this work the inhibitory activity was indicated by the logarithm of reciprocal of the luciferase intensity (Table 1).
The luciferase intensity was a relative value, it was indicated as $100 \%$ in the control experiment with the empty peptide expression vector (Real et al. 2004), so the experimental activity of the peptides was indicated with the logarithm of reciprocal of the luciferase intensity.

\section{Descriptor Calculation}

Two web servers were applied to compute the features and number of descriptor values of the peptides. The updated PROFEAT web server could provide 9 groups of structural and physiochemical descriptors with more than 2000 values, including amino acid composition (G1), dipeptide composition (G2), autocorrelation descriptors (G3), compositiontransition-distribution (G4), quasi-sequence order descriptors (G5), pseudo-amino acid composition (G6, PAAC), amphiphilic pseudo-amino acid composition (G7, APAAC), atomic-level topological descriptors (G8), and total amino acid properties (G9, TAAPs) (Zhang et al. 2017), while 12 groups of descriptors could be got from iFeature, including
Table 1 Sequences and activity of RABV P-binding peptides

\begin{tabular}{|c|c|c|c|}
\hline Name & Sequences & Luciferase intensity & Activity \\
\hline $\mathrm{C} 1$ & CKFCYGSAQCPTFLFIVRLLRFVWV & 0.04 & 1.40 \\
\hline $\mathrm{C} 2$ & CTMCRYQQNCFTRRLIVGGMLLVFV & 0.02 & 1.70 \\
\hline $\mathrm{C} 3$ & CYSCPCERRCHKIARGLLILRSVLF & 0.04 & 1.40 \\
\hline $\mathrm{C} 4$ & CQRCGWETGVGVSGFLVRILRFVVL & 0.04 & 1.40 \\
\hline C5 & CTQCCAPSTCLNYRIFVGLLRFVVI & 0.06 & 1.26 \\
\hline C6 & CDSCERCWYVWLILLRVRLRLLVSL & 0.03 & 1.52 \\
\hline C7 & CKSCDTRCTCLRRRLRVGVGLPCMGC & 0.05 & 1.30 \\
\hline $\mathrm{C} 8$ & CRCCELKSLCPTLMRVVRLLGLVLL & 0.01 & 2.0 \\
\hline C9 & CLCCDKVRTCRRLLGLVMVLSVVRC & 0.03 & 1.52 \\
\hline $\mathrm{C} 10$ & CGECGGGHIVGRFCMVVRFLRLVFI & 0.03 & 1.60 \\
\hline $\mathrm{C} 26$ & CVTCKSTVLCDKMQHPCRRGPRCISC & 0.24 & 0.62 \\
\hline $\mathrm{C} 27$ & CGRCLQRACCKYCRLKCRLILFVIF & 0.02 & 1.70 \\
\hline P11 & PPIPIPDPPQRNRPPPRWFISLMVIRIH & 0.46 & 0.34 \\
\hline $\mathrm{P} 12$ & PPRLLDSPEVMVILHLGFRIGLVRLWIH & 0.07 & 1.19 \\
\hline P13 & PPARSSPPMPPNLPPLRRRIILLRFLFH & 0.10 & 1.0 \\
\hline P14 & PPPLPYGPNRNGEPHLRVLLRLLCIRLH & 0.05 & 1.30 \\
\hline P15 & PPRTTPIPHLDVSLHLLILRILRVRVH & 0.04 & 1.46 \\
\hline P16 & PPDVHTPPHALWRLHLSLRVCLVRMWIH & 0.04 & 1.40 \\
\hline P17 & PPTSPLLPTVNLRPPPIIIVFLLRVWFH & 0.04 & 1.44 \\
\hline P18 & PPLYGRDPTTRRMPHLLLRCCLLRLVVH & 0.08 & 1.10 \\
\hline P19 & PPDQTTYPSAECPPPPLVSILLIGLWLH & 0.45 & 0.34 \\
\hline $\mathrm{P} 20$ & PPRGAHRPNSTVVLHLVIRLCLLRFVVH & 0.04 & 1.40 \\
\hline $\mathrm{P} 21$ & PPDTSLLPPVGLHLVVRLFLLRLSVH & 0.05 & 1.30 \\
\hline $\mathrm{P} 22$ & PPGAPPAPFRTHTPPPRMVIVLIRVWCH & 0.06 & 1.26 \\
\hline $\mathrm{P} 23$ & PPGAPPQPDSVCELHLLCVLRLLVIRIH & 0.02 & 1.70 \\
\hline P24 & PPSHSFRPESLERLHLLRRVLLLMRIVH & 0.07 & 1.16 \\
\hline $\mathrm{P} 25$ & PPCYERMPRRLIRPPPLLSVLLILRLCH & 0.12 & 0.92 \\
\hline $\mathrm{P} 28$ & PPLFEDTPMVNSIPPLRVRLFLLRLVFH & 0.05 & 1.30 \\
\hline P29 & PPRGTETPQRCRRLHLVEMLCLVRVVFH & 0.03 & 1.60 \\
\hline
\end{tabular}


six groups of common features (G1-G6) and six groups features different from PROFEAT (Chen et al. 2018).

\section{Variable Selection and Modeling}

Descriptors from each server were used to construct models respectively. Genetic algorithm (GA) was mainly used for variable selection, by default, the variance cut-off value was set to 0.0001 and correlation coefficient cut-off value was set to 0.99 , the other parameters were as follows: total number of iterations (100), cross-over probability (1), mutation probability $(0.5 \%)$. Data pretreatment was performed to remove constant and inter-correlated descriptors prior to GA execution.

MLR (multivariable linear regression) and partial least squares (PLS) were selected to construct models. A good QSAR model should be validated both internally and externally, and for such purpose, the dataset was divided into training and test sets by Kennard stone method, Euclidean distance method, and Activity-based method, respectively, PLS QSAR models were built using the training sets, and then validated (externally) by the test sets, the validity and stability of the models were assessed by determination coefficient $\left(\mathrm{R}^{2}\right)$, correlation coefficients of leave-one-out crossvalidation $\left(\mathrm{Q}^{2}\right)$ and external validation $\left(\mathrm{Q}_{\mathrm{ext}}^{2}\right)$.

\section{Optimization of the Inhibitory Peptide P16}

P16 was one of the most active peptides according to Real et al. (2004), which was selected for further improvement. A series of mutated peptides were first derived by single amino acid residue substitution, and the potential activity of these peptides was predicted based on the optimal QSAR model; after three rounds of mutation and selection, those with the highest predicted activity would be the candidates for experimental assay.

\section{Docking Analysis of the Peptides and the Phosphoprotein}

Molecular docking was performed using HDock server to analyze the interaction between the peptide and the target phosphoprotein (Yan et al. 2017), the amino acid sequence of which was acquired from GenBank (https://www.ncbi. nlm.nih.gov/protein). The calculated structures were ranked in terms of the lowest energy, and the top-ranked ones were selected.

\section{Activity Testing of the Candidate Peptide}

One of the candidates and P16 as a control were chemically synthesized. In order to deliver them into the cells, the cell penetrating peptide (CPP) 'RRRRRRRRR' was linked to the
$\mathrm{N}$ terminus of each synthesized peptide. The cultured BSR cells were infected with $0.01 \mathrm{MOI}$ of RABV strain CVS, and $1 \mathrm{~h}$ later, the peptide was added to each culture with final concentrations from 0 to $50 \mu \mathrm{g} / \mathrm{ml}$, after incubation at $37{ }^{\circ} \mathrm{C}$ for $72 \mathrm{~h}$, fluorescence focus units (FFU) assay was performed to detect viral titers.

\section{Results}

\section{QSAR Modeling of the Inhibitory Peptides}

450 structural and physicochemical variables from feature groups G3, G4, G5 and G9 were obtained by PROFEAT server, while 64 variables from groups G1-G4 and G6 were got by iFeature server. Since redundant variables could lower the robustness and predictive capability of a model, especially when the number of variables was large, 15 and 8 variables were selected by GA for modeling respectively. The results showed that all the models exhibited good performance in stability and predictability $\left(\mathrm{R}^{2}>0.852\right.$, $\mathrm{Q}^{2}>0.601, \mathrm{Q}_{\mathrm{ext}}^{2}>0.595$ ) (Table 2). The PLS model with the best performance $\left(\mathrm{R}^{2}=0.994, \mathrm{Q}^{2}=0.937, \mathrm{Q}_{\mathrm{ext}}^{2}=0.981\right)$ was applied for peptide optimization (Fig. 1).

\section{Interaction Between the Peptides and the Phosphoprotein}

1596 sequences were derived from P16 by amino acid substitution, about 20 derivatives were predicted to have the highest activity based on the QSAR model (Table 3). Molecular docking was performed to analyze the interaction between the peptides and the phosphoprotein. The peptide P16b6 with the highest predicted activity was selected to compare with P16. The docking results showed that both peptides could bind to the phosphoprotein, but the docking energy scores indicated that P16b6 could bind more tightly than P16 (Fig. 2).

\section{Inhibitory Activity Testing of the Candidate Peptide}

The antiviral activity of P16b6 was then tested for validation. The results showed that both P16 and the derivative P16b6 could inhibit the replication of RABV with dosage effect, and the activity of P16b6 was even higher as predicted (Fig. 3). Therefore it could be concluded that the CPP was efficient in intracellular delivery of antiviral peptides.

\section{Discussion}

The complete management of human rabies needs future efforts on antiviral therapy development (Appolinario and Jackson 2015). A variety of new antiviral agents and 
Table 2 Statistical quality of QSAR models based on different methods

\begin{tabular}{|c|c|c|c|c|c|c|}
\hline \multirow[t]{2}{*}{ Feature servers } & \multicolumn{2}{|c|}{ GA-MLR } & \multicolumn{4}{|l|}{ GA-PLS } \\
\hline & $\mathrm{R}^{2}$ & $\mathrm{Q}^{2}$ & Division & $\mathrm{R}^{2}$ & $\mathrm{Q}^{2}$ & $\mathrm{Q}_{\mathrm{ext}}^{2}$ \\
\hline \multirow[t]{3}{*}{ Profeat } & 0.998 & 0.992 & $\mathrm{KS}$ & 0.993 & 0.950 & 0.960 \\
\hline & & & DB & 0.994 & 0.937 & 0.981 \\
\hline & & & $\mathrm{AB}$ & 0.989 & 0.981 & 0.946 \\
\hline \multirow[t]{3}{*}{ iFeature } & 0.852 & 0.710 & $\mathrm{KS}$ & 0.871 & 0.601 & 0.595 \\
\hline & & & DB & 0.856 & 0.654 & 0.731 \\
\hline & & & $\mathrm{AB}$ & 0.858 & 0.667 & 0.761 \\
\hline
\end{tabular}

PROFEAT and iFeature were servers used to calculate the structural and physicochemical feature descriptors from the peptide sequences, respectively

$R^{2}$ determination coefficient, $Q^{2}$ correlation coefficient of leave-one-out cross-validation, $Q_{e x t}^{2}$ correlation coefficient of external validation

$K S$ Kennard stone, $D B$ Euclidean distance based, $A B$ activity based methods were used for dataset division

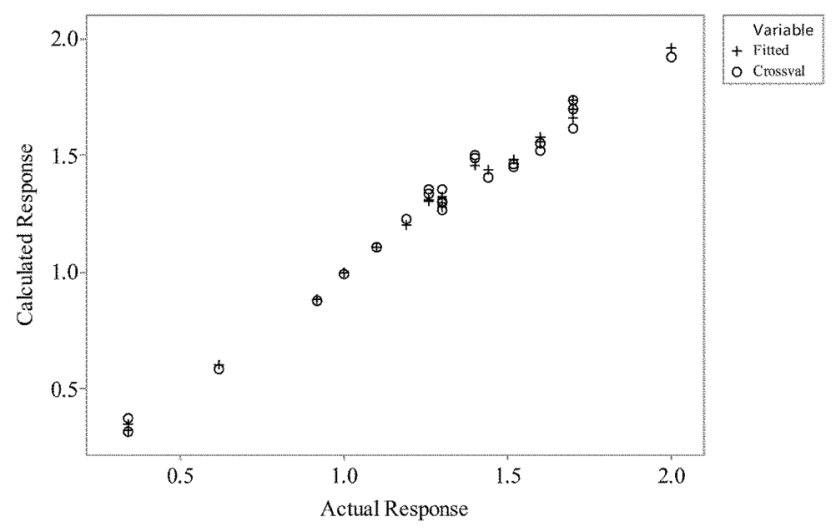

Fig. 1 PLS response plot. The response plot of QSAR model based on Euclidean distance division method, which had the best performance $\left(\mathrm{R}^{2}=0.994, \mathrm{Q}^{2}=0.937, \mathrm{Q}_{\mathrm{ext}}^{2}=0.981\right)$, and was used for peptide design. Response was activity. The plot was produced by minitab 17

approaches are under development and evaluation, including favipiravir (T-705) and RNA interference. T-705 is a broadspectrum RNA polymerase inhibitor, which has been shown to have antiviral activity against RABV, but recent studies showed its effect was limited (Banyard et al. 2017); siRNAbased silencing of target genes has been considered as one of the most promising approaches to fight against this virus, yet how to deliver the drug to the central nervous system safely and efficiently still remains in suspense (Zhu and Guo 2016).

Peptide drugs have been of great interest due to the unique advantages, such as low molecular weight, specificity, and low toxicity (Castel et al. 2009; Kaku et al. 2011). The RABV P-binding peptides screened by Real et al. (2004) provided another choice to fight against RABV, and higher activities will be the primary consideration for their further development.

QSAR is a useful tool for peptide optimization, which can not only reduce the load of experiments, but also explore the action mechanisms (Jenssen 2011). It could be seen from Table 2 that both MLR and PLS models were in good performance, indicating both methods were capable of reflecting the relationship between the peptide features and their activity well, and were suitable for peptide optimization. The peptide P16b6 had proved that by elevated activity. As for the servers to compute the peptide descriptors, both could extract the main features related to the biological activity, but due to fewer descriptors got by iFeature, the models seemed somewhat different.

It was believed that the antiviral peptides functioned by binding with the phosphoprotein to destabilize both the interaction and functionality of the lyssavirus N-P complex (Real et al. 2004), so the inhibitory activity might be determined by the binding force, which was influenced by many properties of the amino acids, such as hydrophobicity, polarity, and charge. Docking analysis showed the peptides could bind to the big pocket of the phosphoprotein, which included several helixes, besides 2 Lys residues on the second helix, there were many hydrophobic amino acids on helix 2 to 6 , so substituting $\mathrm{Ser}^{17}, \mathrm{Cys}^{21}$ and $\mathrm{Ile}^{27}$ of P16 for $\mathrm{Ile}^{17}, \mathrm{Glu}^{21}$ and $\operatorname{Trp}^{27}$ could improve both the hydrophobic and the electrostatic interaction between the peptide and the phosphoprotein, which should account for the activity improvement of P16b6, whereas the secondary structure of the peptide was still in a random coil form mingled with a short helix, which didn't seem to be related to the activity of the peptide (Fig. 4).

Due to the poor permeability, how to use the peptides intracellularly is another issue to be considered. Argininerich segments have been proved to be able to mediate the transmembrane process of a peptide (Bolhassani et al. 2017; Castel et al. 2009; Kristensen and Nielsen 2016; Tashima 2017). In this work, the CPP 'RRRRRRRRR' was effective in transferring the inhibitory peptides into cells.

Figure 3 showed that at low concentrations the antiviral effect of the two peptides had no obvious difference, while 
Table 3 Derivatives of P16 and their predicted activity

\begin{tabular}{lll}
\hline Derivatives & Sequences & Predicted activity \\
\hline P16a1 & PPDVHFPPHALWRLHLILRVCLVRMWFH & 2.75724 \\
P16a2 & PPDVHWPPHALWRLHLILRVCLVRMWFH & 2.74093 \\
P16a3 & PPDVHTPFHALWRLHLILRVCLVRMWFH & 2.70629 \\
P16a4 & PPDVHTPPHALWRLQLILRVCLVRMWFH & 2.70447 \\
P16a5 & PPDVHTPPHALWRLHLILRVDLVRMWFH & 2.67841 \\
P16a6 & PPDVHTPPHALWRLHLILRVELVRMWFH & 2.76685 \\
P16a7 & PPDVHTPPHALWRLHLILRVILVRMWFH & 2.72462 \\
P16a8 & PPDVHTPPHALWRLHLILRVKLVRMWFH & 2.70661 \\
P16a9 & PPDVHTPPHALWRLHLILRVQLVRMWFH & 2.74579 \\
P16a10 & PPDVHTPPHALWRLHLILRVCLVRMHFH & 2.68142 \\
P16b1 & PPDVHFPPHALWRLHLILRVCLVRMWWH & 2.75724 \\
P16b2 & PPDVHWPPHALWRLHLILRVCLVRMWWH & 2.74093 \\
P16b3 & PPDVHTPPHALWRLQLILRVCLVRMWWH & 2.70629 \\
P16b4 & PPDVHTPPHALWRLHLILRVDLVRMWWH & 2.70447 \\
P16b5 & PPDVHTPPHALWRLHLILRVDLVRMWWH & 2.67841 \\
P16b6 & PPDVHTPPHALWRLHLILRVELVRMWWH & 2.76685 \\
P16b7 & PPDVHTPPHALWRLHLILRVILVRMWWH & 2.72462 \\
P16b8 & PPDVHTPPHALWRLHLILRVKLVRMWWH & 2.70661 \\
P16b9 & PPDVHTPPHALWRLHLILRVQLVRMWWH & 2.74579 \\
P16b10 & PPDVHTPPHALWRLHLILRVCLVRMHWH & 2.68142 \\
\hline
\end{tabular}

The activity was predicted with the PLS QSAR model $\left(\mathrm{R}^{2}=0.994, \mathrm{Q}^{2}=0.937, \mathrm{Q}_{\mathrm{ext}}^{2}=0.981\right)$

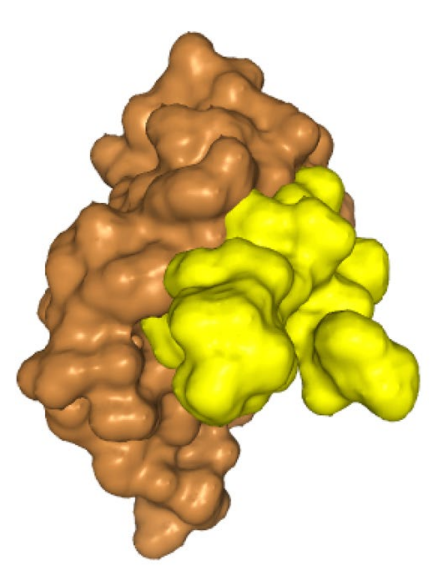

a

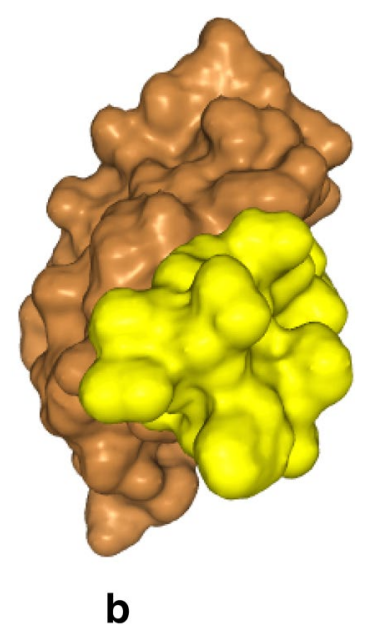

Fig. 2 Docking analysis of the peptides and the phosphoprotein. a Docking result of P16 and the phosphoprotein, the docking energy score was -205.75 ; b Docking result of P16b6 and the phosphoprotein, the docking energy score was -224.56; Docking analysis was performed by HDOCK server, the yellow part indicated the peptide, the brown part indicated the phosphoprotein (Color figure online)

at high concentrations $\mathrm{P} 16 \mathrm{~b} 6$ was more active than $\mathrm{P} 16$, and better antiviral effect depended on higher dosages of peptides, which indicated the inhibitory activity was related not only to the binding force, but also to the amount of peptide in the cell. High concentration might lead to side-effects, such as hemolysis (data not shown), to further improve the

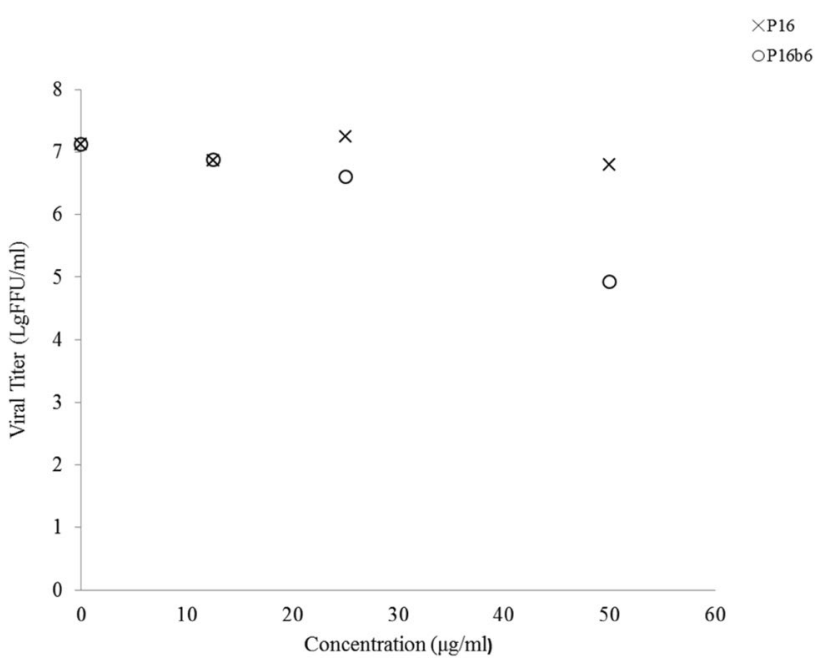

Fig. 3 Antiviral activity comparison of P16 and the derivative P16b6. The cultured BSR cells were infected with RABV strain CVS, the peptides were delivered into the cells by cell penetrating peptide (CPP), and their antiviral activity was compared by testing the viral titers. The plot was produced by Microsoft Excel 2007

activity of the peptide and at the same time to decrease the side-effects should be considered in the future study. Another way to utilize these peptides is to express them in the host cells, provided that a safe and efficient delivery system is available. Alternatively, the optimized peptides can be used as drug leads for nonpeptide design (Real et al. 2004). 


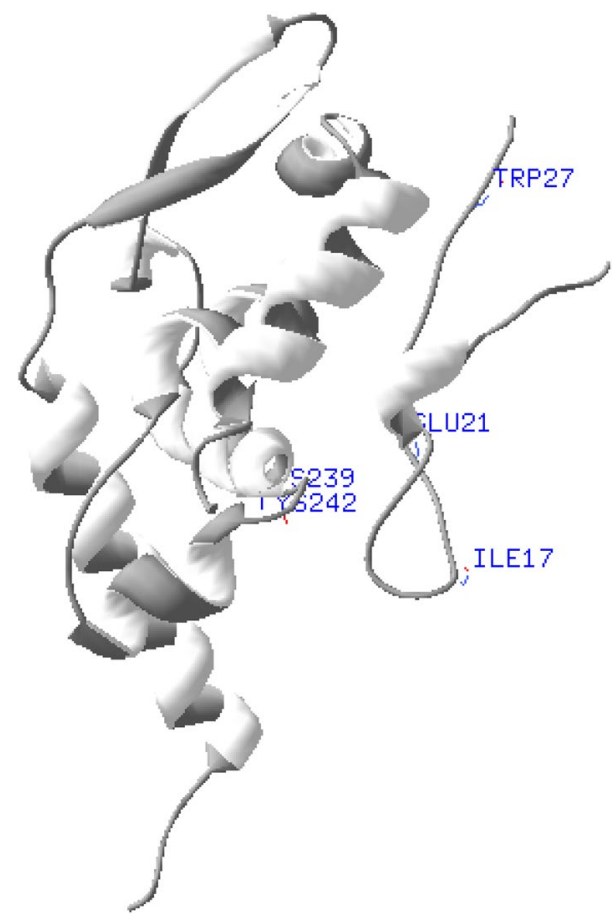

Fig. 4 Binding of P16b6 with the phosphoprotein. The labeled amino acid residues on the peptide were replaced ones, those on the second helix of phosphoprotein were lysine residues. Docking analysis was performed by HDOCK server, and the result was visualized via Swiss-PdbViewer

\section{Conclusions}

Stable and predictable QSAR models were built, which were proved to be useful for anti-RABV peptides design, and these peptides mediated by CPP could inhibit RABV intracellularly. Above all, this study provided an effective way for development of peptide drug against RABV.

Acknowledgements This work was supported by Shandong Provincial Natural Science Foundation, China (Grant No. ZR2016CM25). We thank Shimao Zhu (Shenzhen Weiguang Biological Products Co., Ltd., China) for his generous technical assistance and advice.

Author Contributions LYZ designed the study and wrote the manuscript, CLY built the models, LJ checked and polished the manuscript. All authors read and approved the final manuscript.

\section{Compliance with Ethical Standards}

Conflict of interest The authors declare that they have no conflict of interest.

Ethical Approval No human or animal subjects were involved in the experiments, so an ethical approval was not required.

Informed Consent Informed consent was not required in this study.

\section{References}

Albertini AA, Ruigrok RW, Blondel D (2011) Rabies virus transcription and replication. Adv Virus Res 79:1-22. https://doi. org/10.1016/B978-0-12-387040-7.00001-9

Appolinario CM, Jackson AC (2015) Antiviral therapy for human rabies. Antivir Ther 20(1):1-10. https://doi.org/10.3851/IMP28 516

Banyard AC, Mansfield KL, Wu G, Selden D, Thorne L, Birch C, Koraka P, Osterhaus ADME, Fooks AR (2017) Re-evaluating the effect of Favipiravir treatment on rabies virus infection. Vaccine. https://doi.org/10.1016/j.vaccine.2017.10.109

Bolhassani A, Jafarzade BS, Mardani G (2017) In vitro and in vivo delivery of therapeutic proteins using cell penetrating peptides. Peptides 87:50-63. https://doi.org/10.1016/j.pepti des.2016.11.011

Brunner K, Harder J, Halbach T, Willibald J, Spada F, Gnerlich $F$ et al (2015) Cell-penetrating and neurotargeting dendritic siRNA nanostructures. Angew Chem Int Ed Engl 54(6):19461949. https://doi.org/10.1002/anie.201409803

Castel G, Chtéoui M, Caignard G, Préhaud C, Méhouas S, Réal E et al (2009) Peptides that mimic the amino-terminal end of the rabies virus phosphoprotein have antiviral activity. J Virol 83(20):10808-10820. https://doi.org/10.1128/JVI.00977-09

Chen Z, Zhao P, Li F, Leier A, Marquez-Lago TT, Wang Y, Webb GI, Smith AI, Daly RJ, Chou KC, Song J (2018) iFeature: a Python package and web server for features extraction and selection from protein and peptide sequences. Bioinformatics 34(14):2499-2502. https://doi.org/10.1093/bioinformatics/bty 140

Fouquet B, Nikolic J, Larrous F, Bourhy H, Wirblich C, LagaudrièreGesbert C et al (2015) Focal adhesion kinase is involved in rabies virus infection through its interaction with viral phosphoprotein P. J Virol 89(3):1640-1651. https://doi.org/10.1128/JVI.02602-14

Gnanadurai CW, Huang CT, Kumar D, Zhen F (2015) Novel approaches to the prevention and treatment of rabies. Int J Virol Stud Res 3(1):8-16. https://doi.org/10.19070/2330-0027-150002

Gumpper RH, Li W, Castañeda CH, Scuderi MJ, Bashkin JK, Luo M (2018) A polyamide inhibits replication of vesicular stomatitis virus by targeting RNA in the nucleocapsid. J Virol 92(8):e00146-18. https://doi.org/10.1128/JVI.00146-18

Jackson AC (2016) Human Rabies: a 2016 update. Curr Infect Dis Rep 18(11):38. https://doi.org/10.1007/s11908-016-0540-y

Jenssen H (2011) Descriptors for antimicrobial peptides. Expert Opin Drug Discov 6(2):171-184. https://doi.org/10.1517/17460 441.2011.545817

Kaku Y, Noguchi A, Hotta K, Yamada A, Inoue S (2011) Inhibition of rabies virus propagation in mouse neuroblastoma cells by an intrabody against the viral phosphoprotein. Antiviral Res 91(1):64-71. https://doi.org/10.1016/j.antiviral.2011.04.016

Kammouni W, Wood H, Saleh A, Appolinario CM, Fernyhough P, Jackson AC (2015) Rabies virus phosphoprotein interacts with mitochondrial Complex I and induces mitochondrial dysfunction and oxidative stress. J Neurovirol 21(4):370-382. https:// doi.org/10.1007/s13365-015-0320-8

Kammouni W, Wood H, Jackson AC (2017) Serine residues at positions 162 and 166 of the rabies virus phosphoprotein are critical for the induction of oxidative stress in rabies virus infection. J Neurovirol 23:358-368. https://doi.org/10.1007/s13365-016-0506-8

Kaur M, Garg R, Singh S, Bhatnagar R (2015) Rabies vaccines: where do we stand, where are we heading? Expert Rev Vaccines 14(3):369-381. https://doi.org/10.1586/14760584.2015.973403

Kristensen M, Nielsen HM (2016) Cell-penetrating peptides as tools to enhance non-injectable delivery of biopharmaceuticals. Tissue Barriers 4(2):e1178369. https://doi.org/10.1080/21688 370.2016.1178369 
Lama Z, Gaudin Y, Blondel D, Lagaudrière-Gesbert C (2019) Kinase inhibitors tyrphostin 9 and rottlerin block early steps of rabies virus cycle. Antiviral Res 168:51-60. https://doi.org/10.1016/j. antiviral.2019.04.014

Lingappa UF, Wu X, Macieik A, Yu SF, Atuegbu A, Corpuz M et al (2013) Host-rabies virus protein-protein interactions as druggable antiviral targets. Proc Natl Acad Sci USA 110(10):E861-8. https ://doi.org/10.1073/pnas.1210198110

Masatani T, Ozawa M, Yamada K, Ito N, Horie M, Matsuu A et al (2016) Contribution of the interaction between the rabies virus $\mathrm{P}$ protein and I-kappa B kinase $\epsilon$ to the inhibition of type I IFN induction signalling. Gen Virol 97(2):316-326. https://doi. org/10.1099/jgv.0.000362

Meshram CD, Singh NK, Sonwane AA, Pawar SS, Mishra BP, Chaturvedi VK et al (2013) Evaluation of single and dual siRNAs targeting rabies virus glycoprotein and nucleoprotein genes for inhibition of virus multiplication in vitro. Arch Virol 158(11):2323-2332. https://doi.org/10.1007/s00705-013-1738-z

Okada K, Ito N, Yamaoka S, Masatani T, Ebihara H, Goto H et al (2016) Roles of the rabies virus phosphoprotein isoforms in pathogenesis. J Virol 90(18):8226-8237. https://doi.org/10.1128/ JVI.00809-16

Real E, Rain JC, Battaglia V, Jallet C, Perrin P, Tordo N et al (2004) Antiviral drug discovery strategy using combinatorial libraries of structurally constrained peptides. J Virol 78(14):7410-7417. https ://doi.org/10.1128/JVI.78.14.7410-7417.2004

Singh NK, Meshram CD, Sonwane AA, Dahiya SS, Pawar SS, Chaturvedi VK et al (2014) Protection of mice against lethal rabies virus challenge using short interfering RNAs (siRNAs) delivered through lentiviral vector. Mol Biotechnol 56(2):91-101. https:// doi.org/10.1007/s12033-013-9685-1
Tashima T (2017) Intelligent substance delivery into cells using cellpenetrating peptides. Bioorg Med Chem Lett 27(2):121-130. https ://doi.org/10.1016/j.bmcl.2016.11.083

Wiltzer L, Okada K, Yamaoka S, Larrous F, Kuusisto HV, Sugiyama M et al (2014) Interaction of rabies virus P-protein with STAT proteins is critical to lethal rabies disease. J Infect Dis 209(11):1744 1753. https://doi.org/10.1093/infdis/jit829

Yan Y, Zhang D, Zhou P, Li B, Huang SY (2017) HDOCK: a web server for protein-protein and protein-DNA/RNA docking based on a hybrid strategy. Nucleic Acids Res 45(W1):W365-W373. https://doi.org/10.1093/nar/gkx407

Yousaf MZ, Qasim M, Zia S, Khan Mu, Ashfaq UA, Khan S (2012) Rabies molecular virology, diagnosis, prevention and treatment. Virol J 9:50. https://doi.org/10.1186/1743-422X-9-50

Zhang P, Tao L, Zeng X, Qin C, Chen SY, Zhu F et al (2017) PROFEAT update: a protein features web server with added facility to compute network descriptors for studying omics-derived networks. J Mol Biol 429(3):416-425. https://doi.org/10.1016/j. jmb.2016.10.013

Zhu S, Guo C (2016) Rabies control and treatment: from prophylaxis to strategies with curative potential. Viruses 8(11):279. https:// doi.org/10.3390/v8110279

Publisher's Note Springer Nature remains neutral with regard to jurisdictional claims in published maps and institutional affiliations. 